\title{
In Vivo and In Vitro Quantification of Glucose Kinetics: From Bedside to Bench
}

\author{
Il-Young Kim ${ }^{1,2}$, Sanghee Park ${ }^{1,2}$, Yeongmin Kim ${ }^{3}$, Yewon Chang ${ }^{3}$, Cheol Soo Choi ${ }^{1,2}$, Sang-Hoon Suh ${ }^{4}$, \\ Robert R. Wolfe
}

${ }^{1}$ Department of Molecular Medicine, College of Medicine, Gachon University; ${ }^{2}$ Korea Mouse Metabolic Phenotyping Center, Lee Gil Ya Cancer and Diabetes Institute, Gachon University; ${ }^{3}$ Department of Health Sciences and Technology, Gachon Advanced Institute for Health Sciences \& Technology (GAIHST), Gachon University, Incheon; ${ }^{4}$ Department of Physical Education, Yonsei University, Seoul, Korea; ${ }^{5}$ Department of Geriatrics, the Center for Translational Research in Aging \& Longevity, Donald W. Reynolds Institute on Aging, University of Arkansas for Medical Sciences, Little Rock, AR, USA

Like other substrates, plasma glucose is in a dynamic state of constant turnover (i.e., rates of glucose appearance $\left[R_{a}\right.$ glucose $]$ into and disappearance $\left[R_{d}\right.$ glucose] from the plasma) while staying within a narrow range of normal concentrations, a physiological priority. Persistent imbalance of glucose turnover leads to elevations (i.e., hyperglycemia, $R_{a}>R_{d}$ ) or falls (i.e., hypoglycemia, $R_{a}<R_{d}$ ) in the pool size, leading to clinical conditions such as diabetes. Endogenous $R_{a}$ glucose is divided into hepatic glucose production via glycogenolysis and gluconeogenesis (GNG) and renal GNG. On the other hand, $R_{d}$ glucose, the summed rate of glucose uptake by tissues/organs, involves various intracellular metabolic pathways including glycolysis, the tricarboxylic acid (TCA) cycle, and oxidation at varying rates depending on the metabolic status. Despite the dynamic nature of glucose metabolism, metabolic studies typically rely on measurements of static, snapshot information such as the abundance of mRNAs and proteins and (in)activation of implicated signaling networks without determining actual flux rates. In this review, we will discuss the importance of obtaining kinetic information, basic principles of stable isotope tracer methodology, calculations of in vivo glucose kinetics, and assessments of metabolic flux in experimental models in vivo and in vitro.

Keywords: Stable isotope tracers; Metabolic fluxomics; Insulin resistance; Diabetes mellitus

\section{INTRODUCTION}

Only a few grams of glucose (i.e., the plasma glucose pool size, $100 \mathrm{mg} / \mathrm{dL}$ blood or $3 \mathrm{~g}$ for a $70 \mathrm{~kg}$ healthy person with a plas-

Received: 16 November 2020, Revised: 19 November 2020,

Accepted: 27 November 2020

Corresponding authors: Il-Young Kim

Department of Molecular Medicine, Lee Gil Ya Cancer and Diabetes Institute Gachon University School of Medicine, 155 Gaetbeol-ro, Yeonsu-gu, Incheon 21999, Korea

Tel: +82-32-899-6685, E-mail: iykim@gachon.ac.kr

Sang-Hoon Suh

Department of Physical Education, Yonsei University, 50 Yonsei-ro, Seodaemun-

gu, Seoul 03722, Korea

Tel: +82-2-2123-6187, E-mail: ssh@yonsei.ac.kr ma volume of $3 \mathrm{~L}$ ) circulate in the blood, which supplies all the necessary fuels (i.e., glucose) to critical organs such as the brain. Accordingly, the maintenance of the infinitesimal size of this plasma glucose pool, a physiological priority, is typically stable

\section{Copyright $\odot 2020$ Korean Endocrine Society}

This is an Open Access article distributed under the terms of the Creative Commons Attribution Non-Commercial License (https://creativecommons.org/ licenses/by-nc/4.0/) which permits unrestricted non-commercial use, distribution, and reproduction in any medium, provided the original work is properly cited. 
in healthy individuals, even in perturbed situations such as during exercise [1-7] or after a meal intake [8,9]. For example, even following a $75 \mathrm{~g}$ glucose challenge (25 times the plasma pool size, similar to the amount of sugar contained in two regular Cokes), the plasma glucose concentrations typically do not rise above $200 \mathrm{mg} / \mathrm{dL}$ ( $<2$-fold the pool size) and then return to the baseline within 2 hours in healthy individuals [8,10], as opposed to the insulin-resistant state [11] or diabetic conditions $[12,13]$. The tight regulation of blood glucose concentrations is achieved through the cooperative interplay among multiple organs including the brain, liver, pancreas, muscle, and adipose tissue at multiple levels of regulation [9,14]. Regardless of the complexity of control network for glucose metabolism, however, the plasma glucose pool size is regulated through changes in the rate of glucose appearance ( $R_{a}$ glucose) into blood from all sources and the rate of glucose disappearance or disposal $\left(R_{d}\right.$ glucose, or peripheral glucose uptake) from the blood $[15,16]$. Thus, the plasma glucose concentrations are constant as long as there is a close match between two rates, regardless of their actual rates. However, a persistent imbalance between $R_{a}$ and $R_{d}$ glucose leads to a fall $\left(R_{a}<R_{d}\right)$ or a rise $\left(R_{a}>R_{d}\right)$ in the plasma glucose pool size or concentrations (if we assume that total plasma volume is constant), ultimately leading to clinical conditions including diabetes, coma, and even death $[17,18]$. Changes in the plasma glucose pool size or concentrations do not reveal the dynamic status of glucose metabolism (i.e., metabolic flux). Therefore, it is crucial to obtain dynamic information (i.e., metabolic flux or kinetics) for elucidating the origins of metabolic dysregulation. The determination of metabolic flux can be accomplished with the use of stable isotope tracer methodology, which can be used in conjunction with traditional tools of cellular and molecular biology for an in-depth understanding of metabolism. In this review, we will discuss the following: (1) the importance of obtaining dynamics (i.e., metabolic kinetics) of glucose metabolism; (2) basic principles of stable isotope tracer methodology; (3) calculations of selected in vivo glucose kinetics in steady- and non-steady states; and (4) biological applications of assessments of metabolic flux in vivo (in mice) and in vitro (in cell lines).

\section{Dynamics vs. static, snapshot of metabolism: why does it matter?}

An intuitive representation of the importance of obtaining kinetic information rather than simply depending on "snapshot" or static information for a better understanding of metabolic status is depicted in Fig. 1. From the glucose pool size (euglycemia or hyperglycemia), the dynamic status of glucose metabolism (i.e., rates of glucose turnover) cannot be envisioned as it was demonstrated that the rate of glucose turnover varies by 4-fold for a given pool size [19]. Numerous permutations of rates of $R_{a}$ and

\section{Euglycemia}

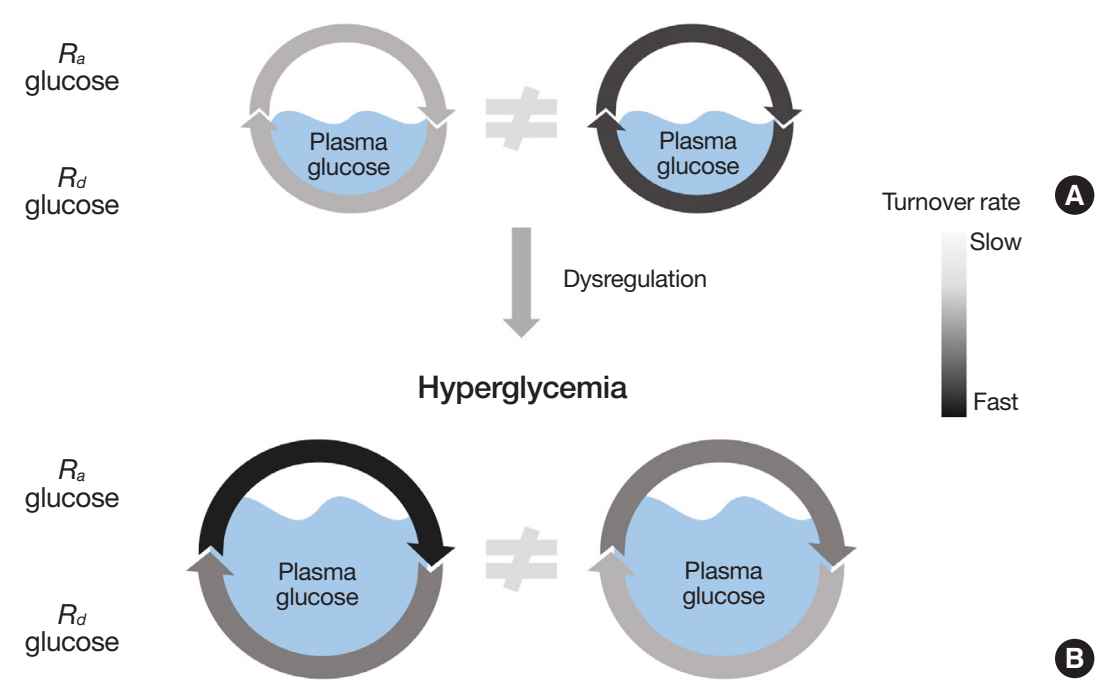

Fig. 1. Static information does not reveal the dynamic nature of glucose metabolism. The plasma glucose pool size is determined by the balance between the rate of glucose appearance $\left(R_{a}\right.$ glucose) into and the rate of glucose disappearance $\left(R_{d}\right.$ glucose) from the plasma compartment. The glucose pool size, whether normal (i.e., euglycemia, A) or abnormal (e.g., hyperglycemia, B), does not reveal the dynamic status of glucose metabolism (i.e., actual metabolic flux rates). 
$R_{d}$ glucose could lead to an identical pool size of glucose in the blood. Despite the dynamic nature of glucose metabolism, metabolic research heavily relies on measurements of static information such as abundance of mRNA, protein, or metabolites, or the activity of cellular signaling cascades regarding metabolic flux rates [20]. While worthwhile, the sole dependence on static, or "snapshot" information regarding the organism's metabolic status can lead to erroneous conclusions on the actual metabolic flux rates. Regarding this notion, numerous examples have been reported in animals [20,21] and humans [22,23]. For example, the duration of fasting time is known to be positively related to the magnitude of gluconeogenesis (GNG) in the liver [21]. In accordance with this notion, it was demonstrated that fasting for over 48 hours in rats showed significant elevations in phosphoenolpyruvate carboxykinase (PEPCK), the enzyme for the first committed step in GNG in the liver [21]. However, the corresponding in vivo flux rate (i.e., GNG) was actually reduced compared to control and 8-hour fasting conditions [21]. This mismatch is not limited to the case of glucose metabolism. Neinast et al. [20] reported that pharmacological inhibition of branched chain $\alpha$-keto acid dehydrogenase kinase resulted in an activation of branched chain $\alpha$-keto acid dehydrogenase, the rate-limiting enzyme for the oxidation of branched chain amino acids (BCAA) without corresponding elevations in the rate of BCAA oxidation. Furthermore, in the field of human muscle protein metabolism, it has often been reported that changes in muscle protein synthetic response to anabolic stimuli such as protein/amino acids and/or resistance exercise are not associated with the activation of implicated signaling molecules (e.g., the mechanistic target of rapamycin complex 1 signaling axis) $[23,24]$. Discrepancies between static information (e.g., enzyme abundance/activity) and actual metabolic flux rates for a given metabolic pathway are due to the fact that the metabolic flux rates are determined by multiple factors including enzyme activity, availability of substrate, and implicated signaling [25]. While it is clear that determining metabolic flux is of critical importance for an understanding of metabolic status in addition to obtaining the traditional static information, in the following section, we will discuss basic principles of stable isotope tracer methodology.

\section{BASIC PRINCIPLES OF STABLE ISOTOPE TRACER METHODOLOGY}

Dynamic information on the metabolic status of substrates including glucose, lipids, amino acids/proteins in organisms (i.e., metabolic flux or kinetics) in vivo and in vitro can be best explored with the introduction of one or more of molecules that are labeled with either a stable or radioactive isotope (i.e., metabolic tracer) into the circulation in the body [11,15,16,26-28]. Here our emphasis will be placed on the applications of stable isotope tracer methodology owing mainly to (1) safety issues, particularly for humans and (2) the versatility of stable isotope tracers in assessing various aspects of metabolism [7,15,16,2935]. In addition, assessments of metabolic flux using stable isotope tracer methodology are typically accomplished in conjunction with the use of gas or liquid chromatography mass spectrometry (GC- or LC-MS) [36,37] or magnetic resonance spectroscopy $[38,39]$ with essentially the same purpose: i.e., determining tracer enrichment (e.g., magnitude of labeling, expressed as various ways) $[15,16]$, which will be briefly discussed below. In this review, our discussion will be based on the use of GC-MS or LC-MS. In this section, we will briefly discuss (1) the meaning of a stable isotope tracer and its enrichment; (2) two basic tracer models for assessing various aspects of metabolic kinetics; and (3) calculations of glucose kinetics in different biological states. More comprehensive and detailed information is available elsewhere [15,16,40-43].

\section{Stable isotope tracers}

Glucose occurs naturally in varying masses with a distinct distribution pattern due to the existence of varying numbers $(M+0$, $M+1, M+2, \ldots$ ) of heavier isotopes (e.g., ${ }^{13} \mathrm{C},{ }^{2} \mathrm{H},{ }^{17} \mathrm{O}$, and/or ${ }^{18} \mathrm{O}$ ) incorporated in the molecule (Fig. 2A). The most abundant mass of glucose is the lowest one $(M+0 ; 180$ molecular weight [MW]) consisting only of the lowest mass of the respective elements (i.e., $6 \times{ }^{12} \mathrm{C}+12 \times{ }^{1} \mathrm{H}+6 \times{ }^{16} \mathrm{O}=180 \mathrm{MW}$ ). Any glucose molecule heavier than $M+0$ can be used as a metabolic tracer for tracing the metabolism of an endogenous tracee (e.g., glucose) and related metabolic pathways. Fig. 2B shows several examples of glucose tracers labeled with ${ }^{13} \mathrm{C}$ at the carbon 1 position $\left(\left[1-{ }^{13} \mathrm{C}\right]\right.$ glucose $)$ or all carbon positions ([U- $\left.{ }^{13} \mathrm{C}_{6}\right]$ glucose; uniformly [U]) or labeled with two deuterium atoms at the carbon 6 position (i.e., $\left[6,6-{ }^{2} \mathrm{H}_{2}\right]$ glucose). The selection of ideal tracer(s) is of critical importance for tracing the specific metabolic fates of the tracee of interest [15].

\section{Enrichment: relative tracer abundance}

To follow the fate of the tracee of interest (e.g., glucose), one or more of tracer is administered in different ways such as a bolus injection orally or intraperitonially (IP), constant infusion intravenously (IV), or in combinations into a body compartment 


\section{Distribution pattern of natural glucose abundance}

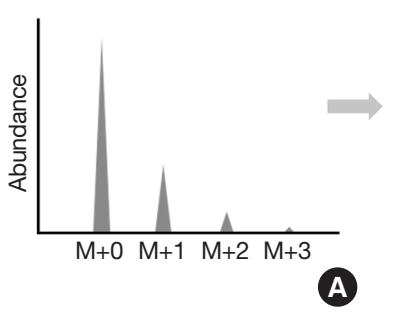

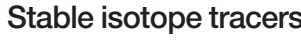

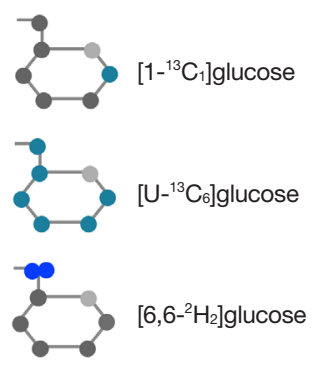

${ }^{13} \mathrm{C} \cdot{ }^{2} \mathrm{H}$

B

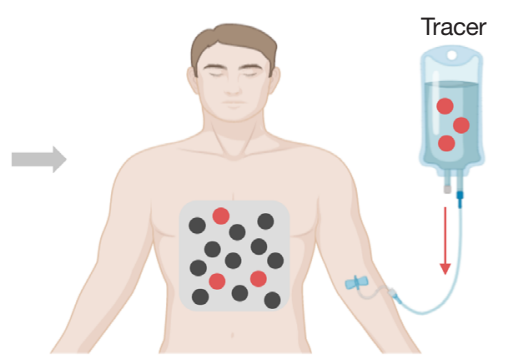

Organisms including human
- Tracee Tracer

Tracer administration

c
Tracer enrichment
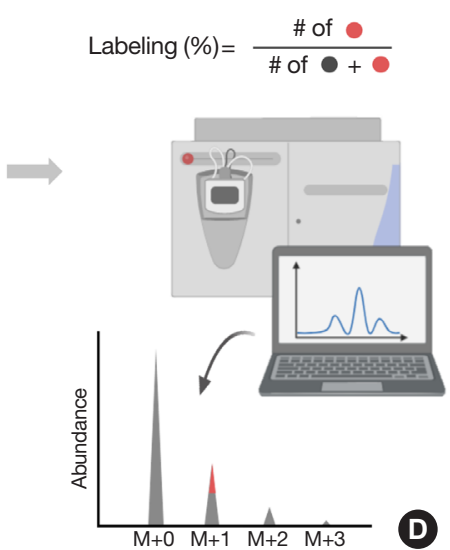

Fig. 2. Stable isotope tracer and its enrichment. Due to the existence of heavier stable isotopes, natural compounds such as glucose have a number of isotopomers with varying masses (A). Typically, $M+0$, the lowest mass, is the most abundant isotopomer of tracee with a mass less than $500 \mathrm{MW}$ (e.g., glucose). Glucose heavier than $M+0$ can be used as a tracer for tracing the fates of the glucose (B) by introducing the tracer into the compartment(s) of a biological system (e.g., blood, tissue, cell, etc.), typically intravenously (C). The magnitude of tracer enrichment (i.e., the relative abundance of tracer that is exogenously introduced into the system to the abundance of the tracee of an identical compound that is endogenously produced) can typically be determined on GC-MS or LC-MS, which is used to calculate metabolic flux. Panels (C, D) were created with BioRender.com. GC-MS, gas chromatography mass spectrometry; LC-MS, liquid chromatography mass spectrometry.

(Fig. 2C) $[15,16,40]$. The next step is to determine tracer enrichment in the compartment when achieving a targeted tracer enrichment. Tracer enrichment is defined as the abundance of tracer relative to the tracee. There are several ways of expressing tracer enrichment, including the TTR and MPE: TTR is the tracer-to-tracee ratio (i.e., the ratio of the number of red circles to the number of black circles), while MPE is mole percent excess (i.e., the ratio of the number of red circles to the sum of all circles, \% labeling) (Fig. 2D). To determine tracer enrichment (either TTR or MPE), the abundance of varying masses of the compound of interest needs to be analyzed by instruments such as GC-MS or LC-MS. In this review, we will use MPE (i.e., \% labeling) for assessing glucose kinetics in vivo and in vitro.

\section{Basic models of tracer methodology}

In a general sense, there are two basic models of tracer methodology to calculate tracee kinetics: (1) the tracer dilution model and (2) the tracer incorporation model (Fig. 3). While the tracer dilution model can be used alone, the tracer incorporation model is used in conjunction with the tracer dilution model in assessing tracee kinetics (e.g., GNG and glucose oxidation). Here we will briefly describe each model in physiological steady states. Non-steady state calculations are more complex and discussed briefly later in this review.

\section{Tracer dilution model}

A schematic representation of the principles of the tracer dilution model is depicted in Fig. 3A. To determine $R_{a}$ tracee (e.g., glucose), a tracer of the same compound (e.g., $\left[6,6-{ }^{2} \mathrm{H}_{2}\right]$ glucose tracer) is constantly infused into the blood at a predefined rate $(F)$, typically after administration of a priming dose of the same glucose tracer (called a primed constant infusion). The practical purpose of administering a priming dose is to reduce the time needed to reach to the point at which tracer enrichment is constant, referred to as plateau enrichment $\left(E_{p}\right)$, while not affecting the magnitude of enrichment at isotopic equilibrium (i.e., $E_{p}$ ). When a tracer is constantly infused into the blood at a given $F$, tracer enrichment will rise and eventually reach $E_{p}$, the magnitude of which is inversely related to the turnover rate of the tracee of interest for a given $F$. At physiological steady states where the pool size is constant, $R_{a}$ tracee is equal to $R_{d}$ tracee. At $E_{p}, R_{a}$ tracer (i.e., $F$ ) is also equal to $R_{d}$ tracer. The relation between $R_{a}$ tracer (i.e., $F$ ) and $R_{a}$ tracee dictates the tracer-to-tracee ratio at $E_{p}$. Thus, the following relations can be established: $F: R_{a}$ glucose $=[$ tracer $]:[$ tracee $]$. After rearrangement of the equation, we can see that $R_{a}$ glucose is the product of $F$ and 1/MPE, which is then equal to $F / E_{p}$. From this relation, it is clear that the magnitude of dilution of the tracer by the tracee in the compartment at $E_{p}$ directly reflects $R_{a}$ tracee. In other words, the faster the tracee turnover, the lower the $E_{p}$ for a given $F$. The tracer dilu- 

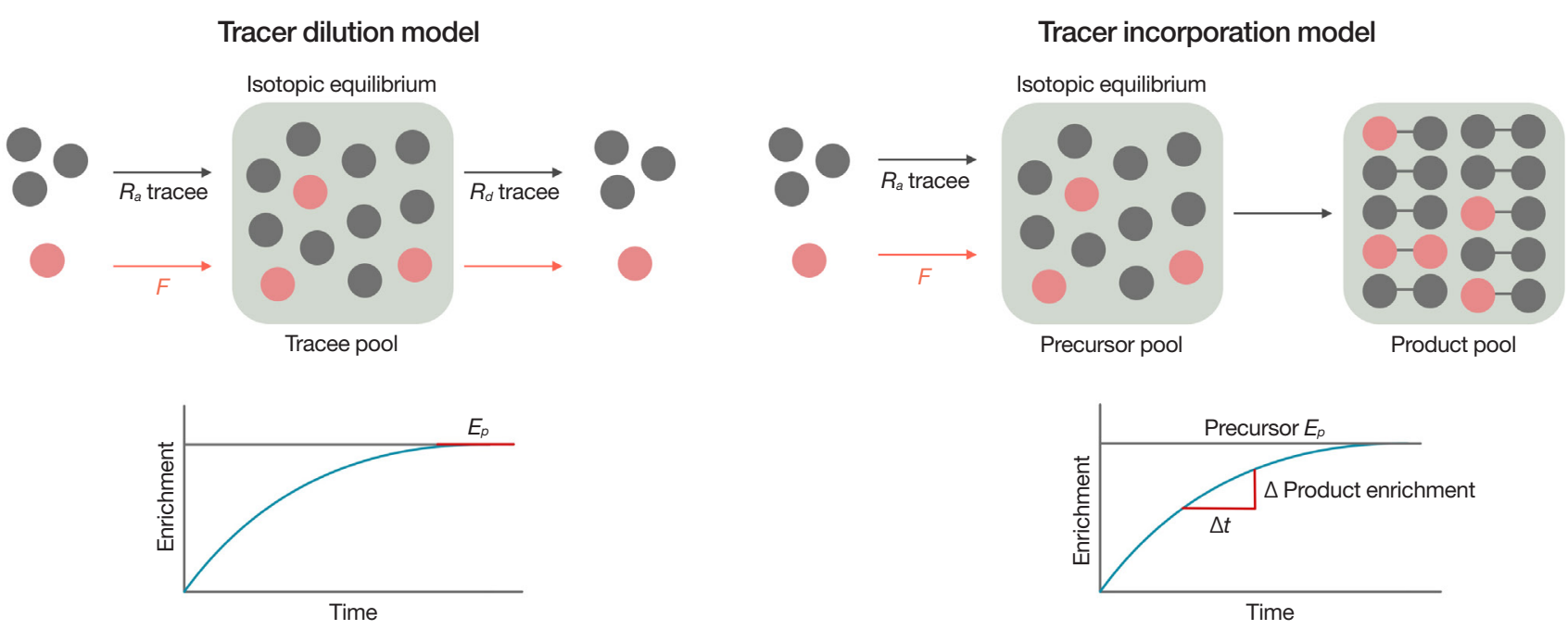

$F / R_{a}$ tracee $=[$ Tracer $][$ Tracee $]$ at plateau

$$
R_{a} \text { tracee }=\frac{F}{E_{p}}
$$

Fig. 3. Basic models of tracer methodology. Calculations of substrate kinetics are predicated on two tracer models: tracer dilution and tracer incorporation models. The tracer dilution model (A) is used to determine $R_{a}$ tracee (e.g., glucose) into a compartment (e.g., blood) based on the magnitude of the dilution of tracer introduced exogenously by the endogenously produced tracee (A). The tracer incorporation model (B) is used to determine the fractional rate of polymer synthesis based on the rate of incorporation of the tracer precursor into the product (e.g., the synthesis of new glucose from a 3-carbon precursor such as alanine, gluconeogenesis). To obtain the absolute rate of synthesis of the product of interest, the value must be multiplied by the pool size (e.g., muscle protein mass) or total production (e.g., hepatic glucose production in the case of gluconeogenesis calculation). FSR, fractional synthesis rate.

tion model can be applicable to assessments of in vivo kinetics of various metabolites including amino acids [26,44-46], palmitate [6,47,48], glycerol [49-51], pyruvate [52], lactate [53-55] as well as glucose $[8,11,56,57]$ in steady states and non-steady states.

\section{Tracer incorporation model}

Alterations in rates of polymer synthesis such as protein [26,58], DNA [59,60], RNA [59,61], triacylglycerol [62,63], and glucose (e.g., GNG) [64,65], from their respective precursors have clinical implications [66,67]. In this regard, the tracer incorporation model has been widely used to obtain the polymer synthesis rate and is predicated on the rate of tracer precursor incorporation to product for a given time period, yielding the fractional synthesis rate (FSR), which refers to the percent of the pool size that has been newly synthesized from the precursor for the most recent defined time period (\%/time) [68]. Fig. 3B represents the schematic principles of the tracer incorporation model to determine polymer FSR. To assess FSR, various precursor tracers can be infused. After achieving isotopic equilibrium of a precursor enrichment (i.e., $E_{p}$ ), labeled and unlabeled precursors will be incorporated into a product (made of two identical monomers, like the synthesis of glucose from two 3-carbon precursors) in pro- portion to their relative abundance (i.e., precursor enrichment). Thus, the magnitude of product enrichment will be determined by (1) the precursor enrichment at $E_{p}$ and (2) the rate of product synthesis [69]. FSR is calculated as the change in product enrichment divided by precursor enrichment (assumed to be constant) multiplied by 100 (for the expression as \%/time) for a given time period. As its definition implies, FSR is a relative term, denoting the $\%$ of the product pool size that has been newly synthesized in the most recent time period. Thus, to obtain the absolute synthesis rate, the FSR term must be multiplied by the pool size (or the production rate of the polymer product when it is released into other compartments, like glucose). The importance of obtaining absolute rates becomes clear when comparing FSRs between two distinct pool sizes (one being half of the other). In this case, an identical muscle protein FSR obtained from two heterogenous groups translates to 2-fold differences in the absolute muscle protein synthesis rate. If one can assume the pool size is similar between groups or constant over the experimental time period, then the simple comparison of FSRs is valid $[70,71]$. The incorporation model can be applicable to the assessments of the kinetic calculations of various compounds, including the FSR of individual proteins $[72,73]$ and subgroups of pro- 
teins (mitochondrial, sarcoplasmic, and mixed muscle protein) [74-79], the substrate oxidation rate [6,80-82], the DNA synthesis rate (thus cell division) $[59,60]$, the nitric oxide synthesis rate from its precursor arginine [83-86], and GNG [30,87], the latter of which will be discussed in the following section in detail.

\section{CALCULATIONS OF IN VIVO GLUCOSE KINETICS}

\section{Overview of glucose metabolism}

A schematic of glucose metabolism from the metabolic flux point of view is depicted (Fig. 4). In this section, the calculations of selected kinetics of in vivo glucose metabolism, centered around systemic glucose kinetics such as hepatic glucose production (HGP) and peripheral glucose uptake (i.e., $R_{d}$ glucose), will be covered in steady state and non-steady state conditions (Fig. 4). In the fasted state, there is apparently no glucose appearing from the gut; instead, it appears endogenously. Endogenous glucose production (EGP) is reflected as $R_{a}$ glu- cose in the fasted state, determined as the $F$ of the glucose tracer divided by the $E_{p}$ of glucose in the plasma. EGP consists of HGP and renal GNG in the fasted states. Further, HGP consists of (1) hepatic glycogenolysis (GB) and (2) hepatic GNG, and contributes most of the EGP. The kidneys contribute to EGP to a very minor extent only through GNG (approximately $5 \%$ of HGP unless in conditions of long-term fasting) [88]. Ignoring renal GNG due to its minimal contribution to EGP, we can assume that HGP equates to EGP. Thus, HGP can be calculated as $R_{a}$ glucose. As HGP is the sum of GB and GNG, either GB or GNG needs to be determined to establish the other. It is typical to assess GNG using various tracer methodologies [64,89,90]. Thus, by knowing HGP and GNG, GB can be inferred from the difference between HGP and GNG, which will be discussed below in more detail. Because the plasma glucose pool in the basal fasted state is constant, $R_{a}$ glucose is equal to $R_{d}$ glucose. $R_{d}$ glucose consists of the sum of the rates of glucose uptake by multiple organs/tissues (i.e., $\sum_{k=1}^{n} R d(k)$ ). To further delineate the fates of $R_{d}$ glucose (i.e., identifications of specific tissues, spe-

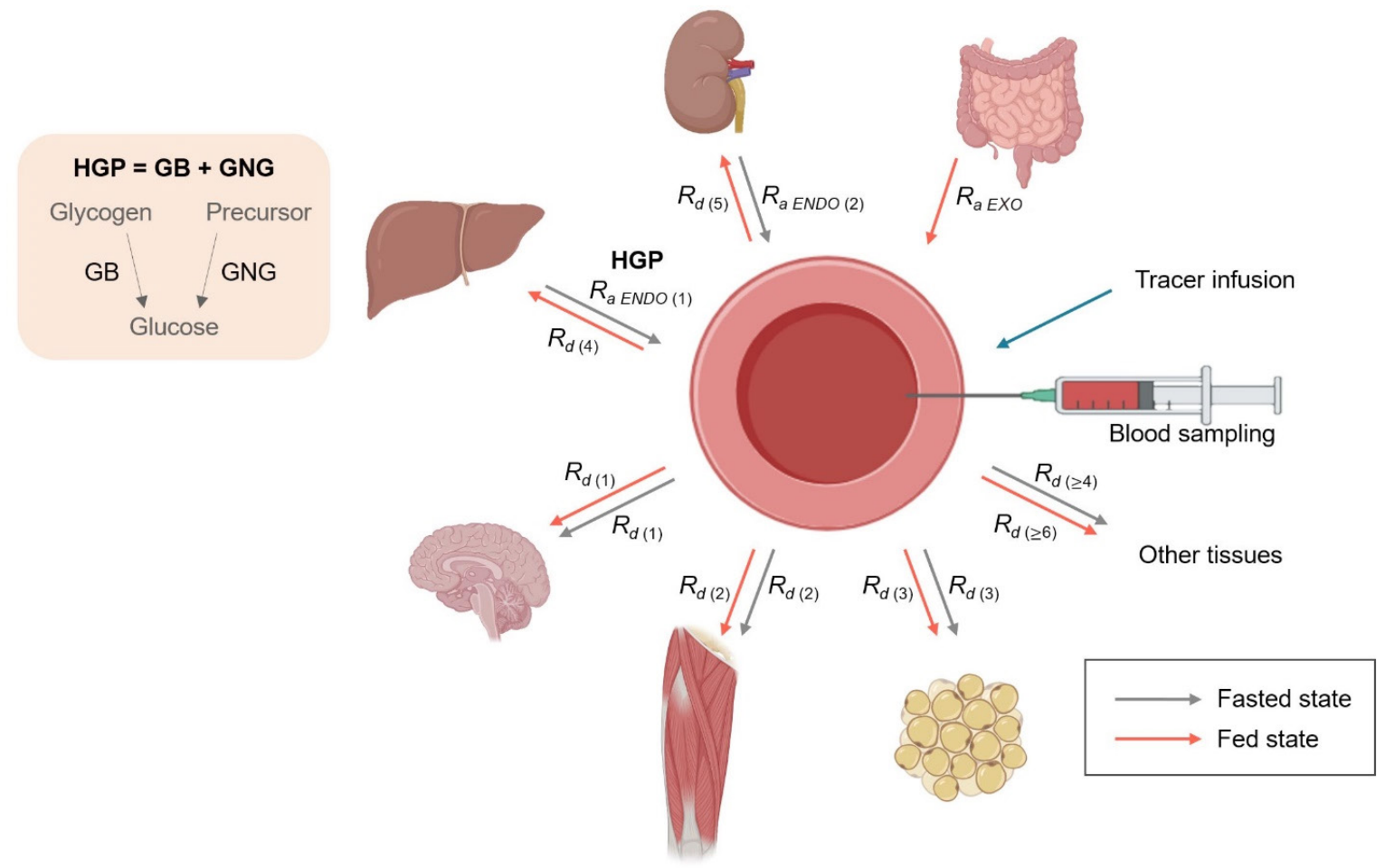

Fig. 4. Overview of systemic glucose metabolism from the kinetic perspective. In the fasted state (gray lines), $R_{a}$ glucose into the blood from the liver (i.e., hepatic glucose production $[\mathrm{HGP}]=$ glycogenolysis $[\mathrm{GB}]$ and gluconeogenesis $[\mathrm{GNG}]$ ) and to a minor extent from the kidneys (renal GNG) reflects endogenous glucose production (EGP). $R_{d}$ glucose reflects the rate of peripheral glucose uptake, which is the sum of all of $R_{d}$ glucose into different tissues/organs both in fasted (gray lines) and fed (red lines) states $\left(\sum_{k=1}^{n} R d(k)\right)$. Unlike the fasted states, $R_{a}$ glucose in the fed states reflects the rate of exogenously introduced glucose (i.e., $R_{a}$ Exo, the rate of glucose appearance from the gut after intake of glucose-containing nutrition) in addition to EGP from the liver and kidneys, which become net glucose consumers, during which time skeletal muscle becomes the largest consumer of glucose. The figure was created with BioRender.com 
cific intracellular metabolic pathways such as glycolysis, mitochondrial tricarboxylic acid [TCA] cycle and pentose pathways within that tissue, etc.) $[42,91,92]$, additional techniques (e.g., deoxyglucose injection, arteriovenous balance, and tissue biopsy for intracellular metabolite labeling) $[93,94]$ may be required. In the fed state such as following a meal intake or a test glucose dose during an oral glucose tolerance test (OGTT), the liver and kidneys become net consumers of plasma glucose. While the brain and the rest of the nervous system are the largest consumers of plasma glucose in the fasted state, skeletal muscles become the largest consumer in the fed state, accounting for up to $85 \%$ of postprandial glucose utilization [95]. In contrast to the fasted state, postprandial $R_{a}$ glucose (i.e., a non-steady state) consists not only of HGP and renal GNG, but also of the contribution from the gut (i.e., $R_{a}$ Exo), originally from food intake. To assess $R_{a}$ Exo, a glucose tracer labeled differently from that infused IV needs to be orally consumed (e.g., $\left[1-{ }^{13} \mathrm{C}\right]$ glucose vs. $\left[6,6-{ }^{2} \mathrm{H}_{2}\right]$ glucose), which will be discussed later in this review. Taken together, the plasma glucose is in a dynamic state of constant turnover with the cooperation of multiple organs to maintain glucose homeostasis. In the following section, we will deal with calculations of these glucose kinetics discussed above in the conditions of fasted and fed states.

\section{Calculations of glucose kinetics in vivo in the basal fasted state}

In the basal fasted state, the plasma glucose pool size is constant, implying a close match between $R_{a}$ glucose (i.e., HGP) and $R_{d}$ glucose. In the basal fasted state, $R_{a}$ glucose $\left(=R_{d}\right.$ glucose) represents EGP or HGP (via GNG and GB) if ignoring renal GNG. To explore the glucose kinetics, we first need to discuss calculations of $R_{a}$ glucose in the basal fasted state.

\section{Endogenous glucose production}

To determine EGP or HGP, one or more blood samples are collected for obtaining background enrichment before tracer administration. Then, after administration of a priming glucose tracer dose (a bolus injection of a glucose tracer), the same glucose tracer is constantly infused IV at a predefined $F$. When $E_{p}$ is reached, blood samples are collected a couple of times for determination of tracer enrichment. Then, the steady state kinetics of the tracee (i.e., $R_{a}$ glucose) can be calculated as $F$ divided by $E_{p}$. For instance, if $\left[6,6-{ }^{2} \mathrm{H}_{2}\right]$ glucose $(M+2)$ is infused constantly at $0.80 \mu \mathrm{mol} / \mathrm{kg} / \mathrm{min}$ following a priming dose of $80 \mu \mathrm{mol} / \mathrm{kg}$, and if the value of $E_{p}$ glucose is $0.04(\mathrm{MPE}=4 \%)$ after subtracting the background enrichment, then $R_{a}$ glucose, calculated as 0.80 $\mu \mathrm{mol} / \mathrm{kg} / \mathrm{min}$ divided by 0.04 , would be $20 \mu \mathrm{mol} / \mathrm{kg} / \mathrm{min}$. Because the plasma glucose pool is constant, $R_{d}$ glucose must be 20 $\mu \mathrm{mol} / \mathrm{kg} / \mathrm{min}$ as well. As discussed above, $R_{a}$ glucose represents EGP, largely reflecting HGP. As HGP is the sum of rates of both hepatic GB and GNG, by knowing GNG, GB can be inferred.

\section{Hepatic gluconeogenesis}

Hepatic GNG is calculated as the product of the fractional contribution of GNG to $\mathrm{HGP}\left(F_{\mathrm{GNG}}\right)$ and $\mathrm{HGP}\left(=R_{a}\right.$ glucose in the fasted state). $F_{\mathrm{GNG}}$ is determined in relation to the precursor (3-carbon sugar) product (i.e., glucose) rule based on the tracer incorporation model as described above. As described in the FSR calculation above, $F_{\mathrm{GNG}}$ is calculated based on the relationship between the enrichment of the product and that of the precursor. While it is straightforward to identify the enrichment of the product, as new glucose appears into the circulation where plasma glucose can be sampled, determination of the "true" precursor enrichment has been a debatable issue over decades $[15,96]$ due to a number of issues that hinder the quantification of "true" precursor enrichment [96,97]. For example, with a primed constant infusion of a precursor tracer (e.g., tracers of glycerol, pyruvate, alanine, or lactate) $[51,52,55,98]$, it is typical to obtain precursor tracer enrichment from plasma (particularly in the case of humans) [52,99] or directly from liver tissue (typically in animal models) $[100,101]$. Problems arise at multiple levels including (1) dilution of tracer en route to glucose in a number of points of metabolic steps and/or (2) gradation of enrichment across liver tissue, which over- or under-estimates "true" GNG [15,102]. Regarding this issue, several solutions have been developed, which are conceptually sound and currently widely used with some practical limitations mostly arising from analytical issues [103]. Among others [102,104], mass isotopomer distribution analysis (MIDA), developed by Hellerstein and Neese [96,103], and heavy water labeling methods [105] bypass the true precursor enrichment issues. In this review, we will briefly discuss the MIDA approach for the calculation of true precursor enrichment due to space limitations. Fig. 5 shows the principle of calculating the true precursor enrichment using MIDA from the pattern of enrichment of the product (glucose) in the plasma regardless of the magnitude of ongoing GB. The principle of MIDA is relatively simple and is predicated on combinatorial probabilities with a binomial expansion: ${ }_{\mathrm{n}} \mathrm{C}_{\mathrm{k}} \times p^{\mathrm{k}} \times(1-p)^{\mathrm{n}-\mathrm{k}}$ where $\mathrm{n}$ is the number of subunits in the product, $k$ is the number of labeled subunits, and $p$ is the labeling probability of the precursor pool $[96,103]$. With an $E_{p}$ of the precursor of 0.5 during a constant infusion of singly labeled pre- 

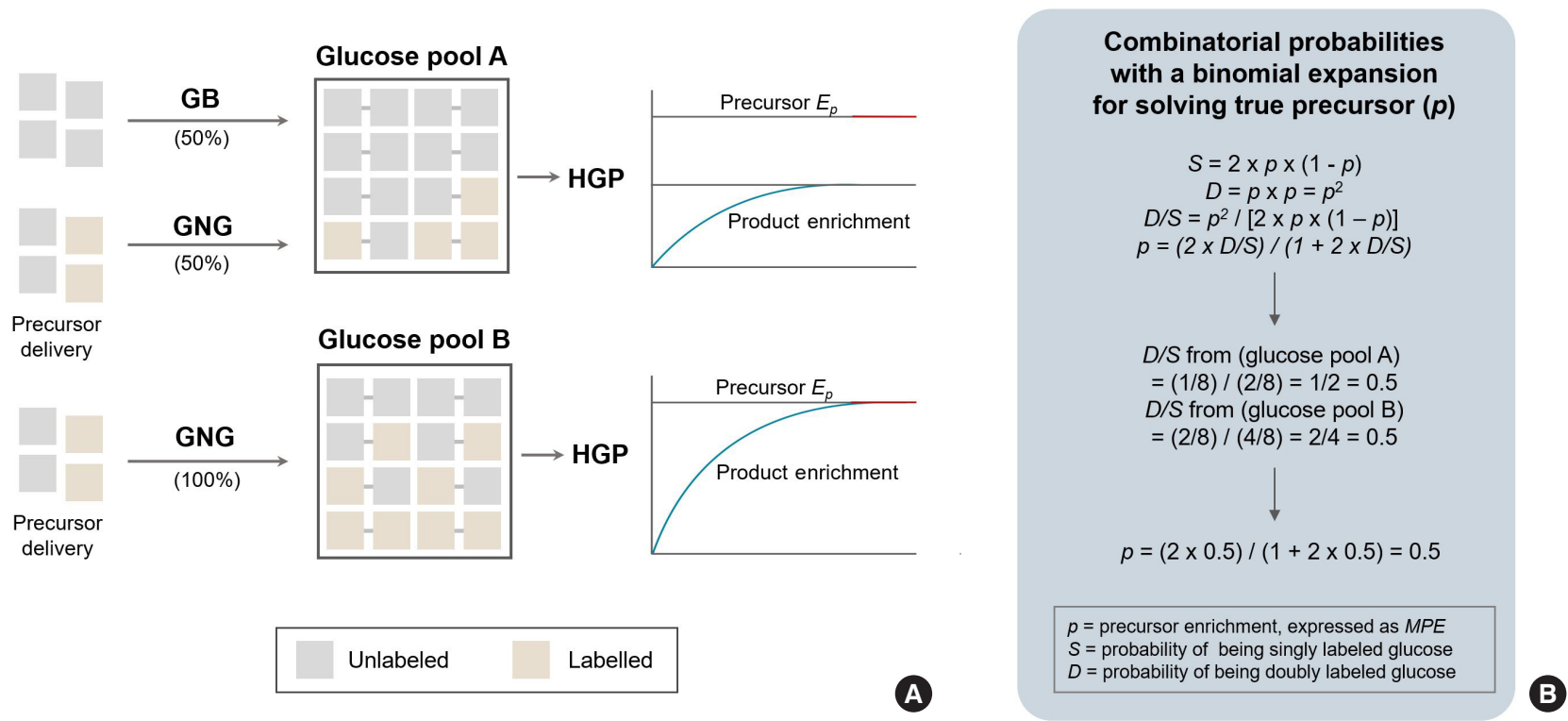

Fig. 5. Principles of "true" precursor enrichment determination using mass isotopomer distribution analysis for estimation of gluconeogenesis (GNG). In the process of GNG, two 3-carbon precursors (labeled and unlabeled) are combined to make a new glucose molecule, and the magnitude of enrichment of the product is determined by the precursor enrichment $(p)$, rate of GNG and the rate of glycogenolysis (GB), latter of which dilutes the product enrichment (A). For a given hepatic glucose production (HGP) and given glucose pool size, "true" precursor enrichment can be back-calculated from the labeling patterns (singly labeled glucose, $S$ vs. doubly labeled glucose, $D$ ) of the product (glucose) based on combinatorial probabilities with a binomial expansion, irrespective of the magnitude of GB (B).

cursor tracer (e.g., $\left[1-{ }^{13} \mathrm{C}\right]$ glycerol), the probabilities of new glucose being both unlabeled (both, black), singly labeled (S), or doubly labeled ( $D$, both red) in case of no GB can be calculated using the equations with the information (for glucose, $n=2, k=1$ for $S$ or $k=2$ for $D$ ) to be 0.25 (i.e., $25 \%$ ), 0.50 (i.e., $50 \%$ ), and 0.25 (i.e., $25 \%$ ) respectively. However, when GB (providing unlabeled glucose to the product pool) contributes $50 \%$ to HGP, the $E_{p}$ of the product (i.e., glucose) will be diluted by half. While $S$ (2/8 for pool A vs. 4/8 for pool B) and $D(1 / 8$ for pool A vs. 2/8 for pool B) may vary depending on the magnitude of GB, the ratio of $D$ to $S(D / S)$ is constant (i.e., 0.5 for both) for a given precursor enrichment. True precursor enrichment can be obtained by solving the equation (i.e., $D / S=p^{2} /[2 \times$ $p \times(1-p)])$ for $p$ by rearranging the equation, i.e., $p=(2 \times D / S) /$ $(1+2 \times D / S)$. Because $D / S$ for both cases is identical, the $p$ values calculated from both cases are identical regardless of occurring GB. Thus, $F_{\mathrm{GNG}}$ is calculated by dividing $E_{p}$ product enrichment by the same $E_{p}$ precursor (0.5): $F_{\mathrm{GNG}}$ of $50 \%$ in Fig. $5 \mathrm{~A}$ and $100 \%$ in Fig. 5B. Thus, the absolute rate of GNG will be the product of HGP and $F_{\mathrm{GNG}}$. Thus, $25 \mu \mathrm{mol} / \mathrm{kg} / \mathrm{min} \times 0.5(50 \%)=$ $12.5 \mu \mathrm{mol} / \mathrm{kg} / \mathrm{min}$. Thus, hepatic GP will be inferred as HGP minus GNG, which is $12.5 \mu \mathrm{mol} / \mathrm{kg} / \mathrm{min}$. In the following, we will deal with the calculation of non-steady state glucose kinetics using an example of an OGTT condition.

\section{Calculations of non-steady state glucose kinetics: Steele equations}

Unlike steady state conditions, it is more complex to calculate tracee kinetics in non-steady state conditions such as after meal intake $[8,11,56]$ and during exercise $[3,4]$, as both the pool size and tracer enrichment of glucose are changing. In this section, we will discuss how to calculate non-steady state glucose kinetics using an example of an OGTT condition $[8,11,56]$. To determine non-steady state glucose kinetics, dual glucose tracers are typically used: one for IV infusion and the other for an oral glucose challenge (e.g., $75 \mathrm{~g}$ glucose consisting of $3.75 \mathrm{~g}$ labeled glucose and $71.25 \mathrm{~g}$ unlabeled glucose, giving an MPE of 5\%). The tracer (e.g., $\left[6,6{ }^{2} \mathrm{H}_{2}\right]$ glucose) for IV infusion is used to trace endogenous $R_{a}\left(R_{a \mathrm{ENDO}}\right)$ and $R_{d}$ glucose, while the oral glucose tracer (e.g., $\left[1-{ }^{13} \mathrm{C}\right]$ glucose contained in a drink mixture with unlabeled one) that is differentially labeled than the one infused is used to trace exogenous $R_{a}$ glucose ( $R_{a \text { ExO }}$ ) from the gut (Fig. 4 , red line). $R_{a}$ glucose in the basal fasted states can be calculated using $F$ of $\left[6,6-{ }^{2} \mathrm{H}_{2}\right]$ glucose $(M+2)$ and its $E_{p}$ from blood samples before the oral glucose challenge as discussed above. Following a glucose challenge, there are decreases in $M+2$ enrichment (i.e., $\left[6,6-{ }^{2} \mathrm{H}_{2}\right]$ glucose) due to the appearance of glucose (largely $M+0$ and $M+1$ ) from the test glucose solution that dilutes $M+2$ enrichment (with the assumption that the oral glu- 
cose tracer is $100 \%$ of $\left[1-{ }^{13} \mathrm{C}\right]$ glucose), while there are increases in $M+1$ enrichment due to the appearance into the circulation of $\left[1-{ }^{13} \mathrm{C}\right]$ glucose $(M+l)$ from the oral glucose. In contrast to the basal fasted state, postprandial $R_{a}$ glucose ( $R_{a}$ тот) is divided into

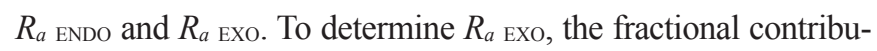

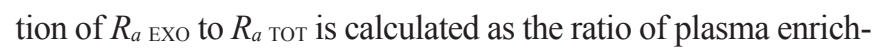
ment $(M+1)$ to drink enrichment $(M+1)$, somewhat similar to the calculation of $F_{\mathrm{GNG}}$, and then multiplied by $R_{a}$ Tот to obtain

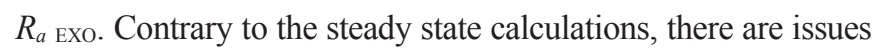
in non-steady states: changes in the pool size and isotopic enrichments that violate assumptions for the calculations of steady state kinetics, which must be accounted for in the calculation of glucose kinetics in non-steady states. Many researchers have developed methods that account for these changes in the glucose pool size and isotopic enrichments in non-steady states for calculations of glucose kinetics [106,107]. The so-called "Steele" equations derived by Steele [107] in 1959 have been most extensively used to account for the nature of non-steady state conditions. The assumptions of the Steele equations include that the compounds of interest being traced in the non-steady state are either distributed in a single pool, or can be described as if the sampled compartment represents a fraction of a single pool. Among others, glucose $[1,56,108,109]$, free fatty acids $[6,7,47]$, glycerol $[110,111]$, and lactate $[53,112]$ in the plasma are compounds that essentially meet the assumptions. The details of the equations will not be discussed here as they are beyond the scope of this review given space limitations [15].

\section{BIOLOGICAL APPLICATIONS TO EXPERIMENTAL MODELS}

The basic principles of stable isotope tracer methodology are applicable to both humans and animals in vivo, as well as to cells in vitro. In contrast to humans, much more detailed flux information can be obtained from animal models (and in vitro models) for a number of reasons including the high accessibility of tissues/organs, feasibility of invasive surgical applications, and availability of large amounts of tissue. In this section, we will briefly cover the procedures of stable isotope tracer studies in mouse models (in vivo) and cell lines (in vitro).

\section{Tracing metabolic flux in vivo in mouse models}

The method of non-radioactive stable isotope tracers in mouse models has been typically used to analyze whole body and tissue metabolism of a substrate of interest and other metabolites derived from the compound (e.g., glucose) due to the advantages mentioned above. Moreover, methods using a variety of tracers have been extensively utilized to study metabolic flux in a variety of clinical conditions (e.g., type 2 diabetes, cancer cachexia, and obesity) [113-115]. In the following section, we will briefly cover the essential procedures of in vivo metabolic flux studies in mouse models, including tracer administration, catheterization surgery, metabolite extraction, enrichment analysis, and flux calculation with an example of assessment of selected aspects of in vivo glucose flux (i.e., $R_{a}$ glucose and oxidation) (Fig. 6).
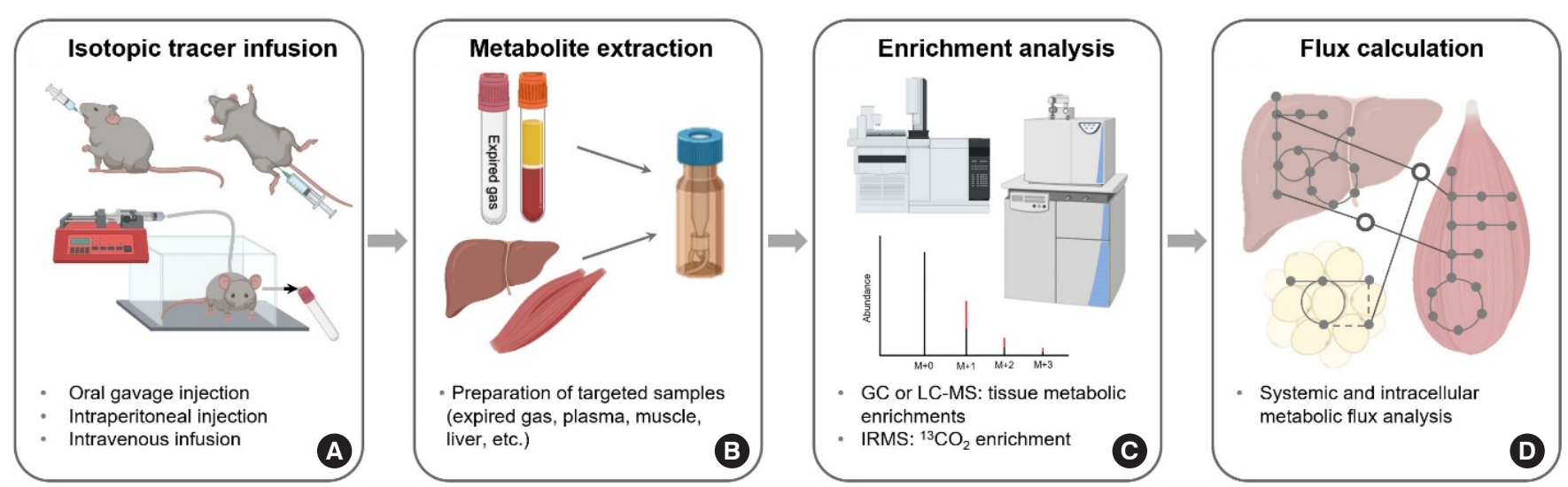

Fig. 6. Overview of the assessment of metabolic flux in a mouse model in vivo. Calculations of metabolic flux rates in vivo in a mouse model is accomplished similarly to the corresponding calculations in humans. Compared to human tracer intravenous (IV) infusion, surgical catheterization for IV infusion via the jugular vein requires an experienced technician in mouse metabolic studies (A). After an appropriate preparation of targeted samples (B), intracellular metabolic rates in addition to the determination of systemic flux rates (such as $R_{a}$ tracee) can be also explored by examining the patterns of mass isotopomer distribution (MID) of downstream metabolites (C, D). The figure was created with BioRender.com. GC-MS, gas chromatography mass spectrometry; LC-MS, liquid chromatography mass spectrometry; IRMS, isotope ratio mass spectrometry. 


\section{Tracer administration and catheterization surgery}

Assessment of glucose metabolism needs to be performed in the conscious state as anesthesia affects glucose homeostasis [116, 117]. Tracer administration can be achieved by using an oral gavage injection, IP injection, or IV infusion (Fig. 6A) [69,117, 118]. While useful in exploring dynamics of metabolism, both oral methods are not practically feasible for assessing absolute rates of glucose turnover due to the inability to achieve $E_{p}$ and the requirement of frequent blood sampling, both of which make kinetic calculations more complicated. In contrast, a (primed) constant infusion method via IV catheterization indwelling on the right jugular vein is a frequently used technique that not only enables the determination of absolute rate of glucose turnover but also avoids excess irritation in response to gavage or IP injection $[69,119]$. However, the surgical procedure of catheterization requires a skillful mouse surgeon, which will be described first.

\section{Surgical catheterization}

Briefly, a median incision, approximately $5 \mathrm{~mm}$, is made at a subtle palpating spot that is approximately $5 \mathrm{~mm}$ on the right side of the trachea, the isolation of the right jugular vein is conducted, and a silastic catheter is inserted into the vessel. The other end of the catheter is tunneled to the back of the neck for two purposes: (1) preventing mice from pulling out and damaging the catheter and (2) easy assessment of the catheter in the tracer infusion experiments. The surgical procedure can be completed in approximately 20 minutes by an experienced mouse surgeon, and it typically takes approximately 5 to 7 days for the mouse to fully recover from the surgery.

\section{Stable isotope tracer infusion}

After a 5 to 15-hour fast (depending on the research question), experimental mice undergo a (primed) constant infusion of ${ }^{13} \mathrm{C}$ glucose. Before and at isotopic equilibrium during the tracer infusion, blood and expired air samples are collected for the calculations of systemic glucose turnover and substrate oxidation, respectively. At the end of the infusion, experimental mice are anesthetized, and tissues are harvested for determining tissue specific metabolic flux.

\section{Metabolite extraction}

Plasma and homogenized tissues are deproteinized. The supernatant containing metabolites is collected, desiccated, and chemically derivatized in order to increase the volatility and stability of metabolites at high temperature on a GC capillary column (Fig. 6B).

\section{Enrichment analysis}

Using GC-MS, the metabolites undergo the separation of substances in GC capillary columns and fragmentation of the substrate of interest. Then, tracer abundance of ion peaks will be counted using selective ion monitoring. To analyze substrate oxidation, isotope ratio mass spectrometry (IRMS) with high detection sensitivity is utilized to measure enrichment of ${ }^{13} \mathrm{CO}_{2}$ from the expired air of the model animals (Fig. 6C).

\section{Flux calculation}

At the end of the procedures, various flux parameters can be calculated (Fig. 6D). First, systemic glucose flux such as $R_{a}$ tracee (e.g., glucose, amino acids, fatty acids) can be calculated based on the tracer dilution model using critical information including $E_{p}$ and $F$ in fasted steady states and $E_{p}, F$, and tracee concentrations (reflection of tracee pool size) in the non-steady state. In addition, intracellular metabolite flux can be estimated via an examination of labeling patterns (i.e., patterns of mass isotopomer distribution [MID]) of each metabolite. Finally, by using ${ }^{13} \mathrm{C}$-labeled substrate as a tracer, the rate of substrate oxidation (e.g., rates of oxidation of glucose, palmitate, leucine, etc.) can be assessed with additional analyses of ${ }^{13} \mathrm{CO}_{2}$ enrichment of expired air and $\mathrm{CO}_{2}$ production from the mice.

\section{${ }^{13} \mathrm{C}$ tracing in metabolic network in vitro using metabolic flux analysis}

Due to its critical implications in the progression of diseases, altered intracellular metabolism has become an attractive target for the development of therapeutics. Therefore, the measurements of detailed status of intracellular metabolism has become more necessary in biomedical research. Stable isotope labeling techniques in vitro can provide intracellular metabolic flux rates in relative terms (through the examination of labeling patterns [MID] of metabolites of interest following tracer treatments) or absolute terms (with the help of computer software such as isotopomer network compartmental analysis [INCA]) [120] in controlled conditions. In this section, we will briefly cover the standardized workflow of metabolic flux analysis (MFA) using representative software (INCA) to measure the absolute rates of intracellular metabolic flux, which has emerged as the primary approach in this regard.

\section{Metabolic flux analysis}

In the process of MFA with the assistance of computer software such as INCA, the labeling patterns of intracellular metabolites (i.e., MID) derived from ${ }^{13} \mathrm{C}$-labeled nutrient(s), cellular uptake 


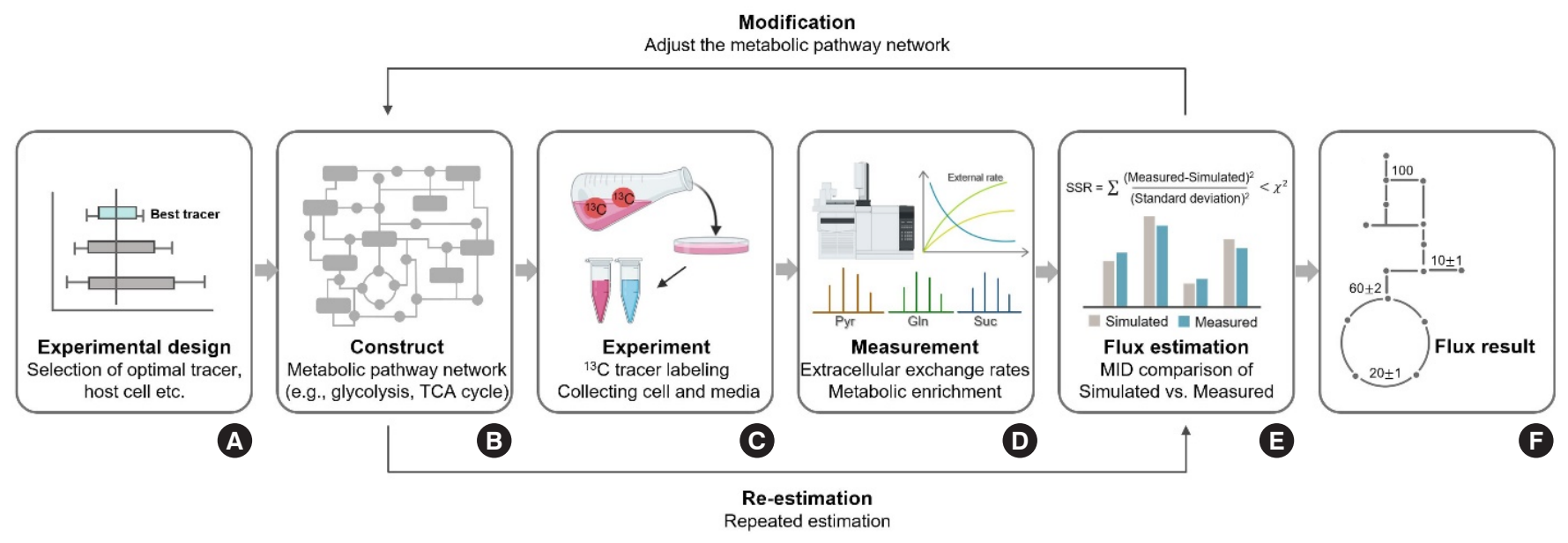

Fig. 7. Overview of the assessment of metabolic flux in vitro using metabolic flux analysis (MFA). The intracellular flux rates of specific metabolic pathways (such as glycolysis, the tricarboxylic acid [TCA] cycle, etc.) can be estimated in vitro through the examination of mass isotopomer distribution (MID) patterns of metabolites (on gas chromatography mass spectrometry [GC-MS]) and external flux rates (e.g., rates of glucose uptake and secretion of lactate) following treatment with tracer(s) (e.g., [U- $\left.{ }^{13} \mathrm{C}_{6}\right]$ glucose) (A-F). Differences between the estimated MIDs and measured MIDs are adjusted through iterative repetitions of model reconstruction and statistical validation processes (back and forth between E and B). Panels (C, D) were created with BioRender.com. SSR, sum-of-squared residual

of the nutrient(s), and secretion rates of selected product(s), and prior knowledge of the metabolic pathway network are combined for computational estimation of metabolic flux [120,121]. To examine intracellular metabolic flux, an experiment is initially designed (Fig. 7A). In the experimental design, the selection of an optimal tracer(s) is best made in silico (i.e., in computer simulations) [122] and is important to ensure an accurate analysis of metabolic flux, followed by constructing a metabolic pathway network for MFA (e.g., glycolysis pathway, pentose phosphate pathway, etc.) (Fig. 7B). A metabolic pathway network can be constructed using databases such as the Kyoto Encyclopedia of Genes and Genomes (KEGG). The next step is to measure external flux rates (e.g., rates of uptake of glucose and/ or glutamine and rates of secretion of lactate and/or pyruvate) based on changes in concentrations of substrate of interest for a defined time period, normalized for the number of cells after treatment of the medium with ${ }^{13} \mathrm{C}$ tracer(s) (Fig. 7C). Sequentially, isotopic labeling patterns (i.e., MID) of intermediates from the cells and medium are determined by using GC-MS (Fig. 7D). With the assistant of MFA software such as INCA, factors including constructed metabolic pathway network, measured external flux rates, and MIDs of intermediates are utilized for flux estimation. Then, through rigorous statistical processes, the goodness-of-fit of the constructed model to the observed values is first verified and then the sum-of-squared residuals between the simulated and measured MID results is minimized through repetitions of model reconstruction (e.g., modeling as- sumptions, additional information from the literature, or novel hypotheses) until being statistically acceptable (Fig. 7E) [123]. The statistically accepted results finally represent the absolute rates of intracellular metabolic flux (Fig. 7F).

\section{CONCLUSIONS}

Like other substrates, the maintenance of normal glucose metabolism is achieved through cooperative orchestrations at multiple levels of regulation including multi-omics and implicated signaling. While worthwhile, static "snapshot" information on metabolism does not reveal the dynamic nature of glucose metabolism, which is in a constant state of turnover (i.e., rates of production, appearance or disappearance, and oxidation of glucose). Stable isotope tracer methodology in metabolic studies is a state-of-the-art technology that allows both clinical and basic researchers to explore metabolic kinetics in various (patho) physiological conditions both in humans and animals in vivo and in vitro. In in vivo animal and in vitro cell studies, stable isotope tracer methodology can enable the determinations not only of systemic flux rates, but also of intracellular metabolic pathway flux rates (i.e., relative flux rates) through the close examination of MID patterns. The absolute intracellular flux rates of a specific metabolic network can also be estimated with the assistance of computer software such as INCA. Taken together, stable isotope tracers can provide an in-depth dynamic assessment of changes in metabolic status in conjunction with simul- 
taneous investigations of the molecular basis of the observed kinetic responses.

\section{CONFLICTS OF INTEREST}

No potential conflict of interest relevant to this article was reported.

\section{ACKNOWLEDGMENTS}

Il-Young Kim: Basic Science Research Program through the National Research Foundation of Korea (NRF) funded by the Ministry of Education (2018R1D1A1B07051053). Korea Research Fellowship (KRF) funded by the Ministry of Sciences and ICT and National Research Foundation of Korea (2019H1D3A1A01071043). Sanghee Park: Basic Science Research Program through the National Research Foundation of Korea (NRF) funded by the Ministry of Education (2020R1I1A1A01074380). Cheol Soo Choi: This research was also supported by the Bio \& Medical Technology Development Program of the National Research Foundation (NRF) funded by the Korean government (MSIT) (No.2014M3A9D5A01073886). Sang-Hoon Suh: Basic Science Research Program through the National Research Foundation of Korea (NRF) funded by the Ministry of Education (MOE) (No. 2017R1D1A1B03032988).

\section{ORCID}

Il-Young Kim https://orcid.org/0000-0002-6314-2415

Sang-Hoon Suh https://orcid.org/0000-0002-8284-4455

\section{REFERENCES}

1. Suh SH, Casazza GA, Horning MA, Miller BF, Brooks GA. Effects of oral contraceptives on glucose flux and substrate oxidation rates during rest and exercise. J Appl Physiol (1985) 2003;94:285-94.

2. Suh SH, Casazza GA, Horning MA, Miller BF, Brooks GA. Luteal and follicular glucose fluxes during rest and exercise in 3-h postabsorptive women. J Appl Physiol (1985) 2002;93:42-50.

3. Weber JM, Klein S, Wolfe RR. Role of the glucose cycle in control of net glucose flux in exercising humans. J Appl Physiol (1985) 1990;68:1815-9.

4. Brooks GA. The precious few grams of glucose during exercise. Int J Mol Sci 2020;21:5733.
5. Wolfe RR, Nadel ER, Shaw JH, Stephenson LA, Wolfe $\mathrm{MH}$. Role of changes in insulin and glucagon in glucose homeostasis in exercise. J Clin Invest 1986;77:900-7.

6. Romijn JA, Coyle EF, Sidossis LS, Rosenblatt J, Wolfe RR. Substrate metabolism during different exercise intensities in endurance-trained women. J Appl Physiol (1985) 2000; 88:1707-14.

7. Romijn JA, Coyle EF, Sidossis LS, Gastaldelli A, Horowitz JF, Endert E, et al. Regulation of endogenous fat and carbohydrate metabolism in relation to exercise intensity and duration. Am J Physiol 1993;265(3 Pt 1):E380-91.

8. Wardle SL, Macnaughton LS, McGlory C, Witard OC, Dick JR, Whitfield PD, et al. Human skeletal muscle metabolic responses to 6 days of high-fat overfeeding are associated with dietary n-3PUFA content and muscle oxidative capacity. Physiol Rep 2020;8:e14529.

9. Meyer C, Dostou JM, Welle SL, Gerich JE. Role of human liver, kidney, and skeletal muscle in postprandial glucose homeostasis. Am J Physiol Endocrinol Metab 2002;282: E419-27.

10. Nathan DM, Davidson MB, DeFronzo RA, Heine RJ, Henry $R R$, Pratley $R$, et al. Impaired fasting glucose and impaired glucose tolerance: implications for care. Diabetes Care 2007;30:753-9.

11. Kim IY, Schutzler SE, Azhar G, Wolfe RR, Ferrando AA, Coker RH. Short term elevation in dietary protein intake does not worsen insulin resistance or lipids in older adults with metabolic syndrome: a randomized-controlled trial. BMC Nutr 2017;3:33.

12. van Haeften TW, Dubbeldam S, Zonderland ML, Erkelens DW. Insulin secretion in normal glucose-tolerant relatives of type 2 diabetic subjects. Assessments using hyperglycemic glucose clamps and oral glucose tolerance tests. Diabetes Care 1998;21:278-82.

13. Gumbiner B, Polonsky KS, Beltz WF, Griver K, Wallace P, Brechtel G, et al. Effects of weight loss and reduced hyperglycemia on the kinetics of insulin secretion in obese noninsulin dependent diabetes mellitus. J Clin Endocrinol Metab 1990;70:1594-602.

14. Rosen ED, Spiegelman BM. Adipocytes as regulators of energy balance and glucose homeostasis. Nature 2006;444: 847-53.

15. Wolfe RR, Chinkes DL. Isotope tracers in metabolic research: principles and practice of kinetic analysis. New York: Wiley-Liss; 2005.

16. Kim IY, Suh SH, Lee IK, Wolfe RR. Applications of stable, 
nonradioactive isotope tracers in in vivo human metabolic research. Exp Mol Med 2016;48:e203.

17. Umpierrez GE, Isaacs SD, Bazargan N, You X, Thaler LM, Kitabchi AE. Hyperglycemia: an independent marker of inhospital mortality in patients with undiagnosed diabetes. J Clin Endocrinol Metab 2002;87:978-82.

18. Qiao Q, Pyorala K, Pyorala M, Nissinen A, Lindstrom J, Tilvis R, et al. Two-hour glucose is a better risk predictor for incident coronary heart disease and cardiovascular mortality than fasting glucose. Eur Heart J 2002;23:1267-75.

19. Reaven GM, Hollenbeck C, Jeng CY, Wu MS, Chen YD. Measurement of plasma glucose, free fatty acid, lactate, and insulin for $24 \mathrm{~h}$ in patients with NIDDM. Diabetes 1988;37: 1020-4.

20. Neinast MD, Jang C, Hui S, Murashige DS, Chu Q, Morscher RJ, et al. Quantitative analysis of the whole-body metabolic fate of branched-chain amino acids. Cell Metab 2019;29:417-29.

21. Perry RJ, Wang Y, Cline GW, Rabin-Court A, Song JD, Dufour S, et al. Leptin mediates a glucose-fatty acid cycle to maintain glucose homeostasis in starvation. Cell 2018; 172:234-48.

22. Robinson MM, Dasari S, Konopka AR, Johnson ML, Manjunatha S, Esponda RR, et al. Enhanced protein translation underlies improved metabolic and physical adaptations to different exercise training modes in young and old humans. Cell Metab 2017;25:581-92.

23. Bukhari SS, Phillips BE, Wilkinson DJ, Limb MC, Rankin D, Mitchell WK, et al. Intake of low-dose leucine-rich essential amino acids stimulates muscle anabolism equivalently to bolus whey protein in older women at rest and after exercise. Am J Physiol Endocrinol Metab 2015;308: E1056-65.

24. Greenhaff PL, Karagounis LG, Peirce N, Simpson EJ, Hazell M, Layfield R, et al. Disassociation between the effects of amino acids and insulin on signaling, ubiquitin ligases, and protein turnover in human muscle. Am J Physiol Endocrinol Metab 2008;295:E595-604.

25. Chubukov V, Uhr M, Le Chat L, Kleijn RJ, Jules M, Link H, et al. Transcriptional regulation is insufficient to explain substrate-induced flux changes in Bacillus subtilis. Mol Syst Biol 2013;9:709.

26. Kim IY, Park S, Jang J, Wolfe RR. Understanding muscle protein dynamics: technical considerations for advancing sarcopenia research. Ann Geriatr Med Res 2020;24:157-65.

27. Kim IY, Deutz NEP, Wolfe RR. Update on maximal ana- bolic response to dietary protein. Clin Nutr 2018;37:411-8.

28. Kim JK. Hyperinsulinemic-euglycemic clamp to assess insulin sensitivity in vivo. Methods Mol Biol 2009;560:22138.

29. Pietzsch J, Julius U, Nitzsche S, Hanefeld M. In vivo evidence for increased apolipoprotein A-I catabolism in subjects with impaired glucose tolerance. Diabetes 1998;47: 1928-34.

30. Hellerstein MK, Neese RA, Linfoot P, Christiansen M, Turner S, Letscher A. Hepatic gluconeogenic fluxes and glycogen turnover during fasting in humans. A stable isotope study. J Clin Invest 1997;100:1305-19.

31. Kim IY, Schutzler SE, Schrader A, Spencer HJ, Azhar G, Deutz NE, et al. Acute ingestion of citrulline stimulates nitric oxide synthesis but does not increase blood flow in healthy young and older adults with heart failure. Am J Physiol Endocrinol Metab 2015;309:E915-24.

32. Kim IY, Schutzler S, Schrader AM, Spencer HJ, Azhar G, Wolfe RR, et al. Protein intake distribution pattern does not affect anabolic response, lean body mass, muscle strength or function over 8 weeks in older adults: a randomizedcontrolled trial. Clin Nutr 2018;37:488-93.

33. Kim IY, Shin YA, Schutzler SE, Azhar G, Wolfe RR, Ferrando AA. Quality of meal protein determines anabolic response in older adults. Clin Nutr 2018;37(6 Pt A):2076-83.

34. Berryman CE, Young AJ, Karl JP, Kenefick RW, Margolis LM, Cole RE, et al. Severe negative energy balance during $21 \mathrm{~d}$ at high altitude decreases fat-free mass regardless of dietary protein intake: a randomized controlled trial. FASEB J 2018;32:894-905.

35. Horowitz JF, Mora-Rodriguez R, Byerley LO, Coyle EF. Lipolytic suppression following carbohydrate ingestion limits fat oxidation during exercise. Am J Physiol 1997; 273:E768-75.

36. Coker RH, Shin K, Scholten K, Johannsen M, Tsigonis J, Kim IY, et al. Essential amino acid-enriched meal replacement promotes superior net protein balance in older, overweight adults. Clin Nutr 2019;38:2821-6.

37. Kim IY, Park S, Smeets ETHC, Schutzler S, Azhar G, Wei JY, et al. Consumption of a specially-formulated mixture of essential amino acids promotes gain in whole-body protein to a greater extent than a complete meal replacement in older women with heart failure. Nutrients 2019;11:1360.

38. Deja S, Fu X, Fletcher JA, Kucejova B, Browning JD, Young JD, et al. Simultaneous tracers and a unified model of positional and mass isotopomers for quantification of 
metabolic flux in liver. Metab Eng 2020;59:1-14.

39. Chaumeil MM, Najac C, Ronen SM. Studies of metabolism using (13)C MRS of hyperpolarized probes. Methods Enzymol 2015;561:1-71.

40. Cobelli C, Foster D, Toffolo, G. Tracer kinetics in biomedical research. Boston: Springer; 2002.

41. Jang C, Chen L, Rabinowitz JD. Metabolomics and isotope tracing. Cell 2018;173:822-37.

42. Liu S, Dai Z, Cooper DE, Kirsch DG, Locasale JW. Quantitative analysis of the physiological contributions of glucose to the TCA cycle. Cell Metab 2020;32:619-28.

43. Kim IY, Park S, Jang J, Wolfe RR. Quantifications of lipid kinetics in vivo using stable isotope tracer methodology. J Lipid Atheroscler 2020;9:110-23.

44. Park S, Jang J, Choi MD, Shin YA, Schutzler S, Azhar G, et al. The anabolic response to dietary protein is not limited by the maximal stimulation of protein synthesis in healthy older adults: a randomized crossover trial. Nutrients 2020; 12:E3276.

45. Park S, Church DD, Azhar G, Schutzler SE, Ferrando AA, Wolfe RR. Anabolic response to essential amino acid plus whey protein composition is greater than whey protein alone in young healthy adults. J Int Soc Sports Nutr 2020; 17:9.

46. Kim IY, Schutzler S, Schrader A, Spencer HJ, Azhar G, Ferrando AA, et al. The anabolic response to a meal containing different amounts of protein is not limited by the maximal stimulation of protein synthesis in healthy young adults. Am J Physiol Endocrinol Metab 2016;310:E73-80.

47. Sidossis LS, Stuart CA, Shulman GI, Lopaschuk GD, Wolfe RR. Glucose plus insulin regulate fat oxidation by controlling the rate of fatty acid entry into the mitochondria. J Clin Invest 1996;98:2244-50.

48. Goodpaster BH, Wolfe RR, Kelley DE. Effects of obesity on substrate utilization during exercise. Obes Res 2002;10: 575-84.

49. Jacobs KA, Casazza GA, Suh SH, Horning MA, Brooks GA. Fatty acid reesterification but not oxidation is increased by oral contraceptive use in women. J Appl Physiol (1985) 2005;98:1720-31.

50. Baba H, Zhang XJ, Wolfe RR. Glycerol gluconeogenesis in fasting humans. Nutrition 1995;11:149-53.

51. Qi J, Lang W, Geisler JG, Wang P, Petrounia I, Mai S, et al. The use of stable isotope-labeled glycerol and oleic acid to differentiate the hepatic functions of DGAT1 and -2. J Lipid Res 2012;53:1106-16.
52. Marjanska M, Iltis I, Shestov AA, Deelchand DK, Nelson C, Ugurbil $\mathrm{K}$, et al. In vivo $13 \mathrm{C}$ spectroscopy in the rat brain using hyperpolarized [1-(13)C]pyruvate and [2-(13)C]pyruvate. J Magn Reson 2010;206:210-8.

53. Miller BF, Fattor JA, Jacobs KA, Horning MA, Navazio F, Lindinger MI, et al. Lactate and glucose interactions during rest and exercise in men: effect of exogenous lactate infusion. J Physiol 2002;544:963-75.

54. Romijn JA, Chinkes DL, Schwarz JM, Wolfe RR. Lactatepyruvate interconversion in blood: implications for in vivo tracer studies. Am J Physiol 1994;266(3 Pt 1):E334-40.

55. Henderson GC, Horning MA, Lehman SL, Wolfel EE, Bergman BC, Brooks GA. Pyruvate shuttling during rest and exercise before and after endurance training in men. $\mathrm{J}$ Appl Physiol (1985) 2004;97:317-25.

56. Kim IY, Williams RH, Schutzler SE, Lasley CJ, Bodenner DL, Wolfe RR, et al. Acute lysine supplementation does not improve hepatic or peripheral insulin sensitivity in older, overweight individuals. Nutr Metab (Lond) 2014;11:49.

57. Chopra S, Rathore A, Younas H, Pham LV, Gu C, Beselman A, et al. Obstructive sleep apnea dynamically increases nocturnal plasma free fatty acids, glucose, and cortisol during sleep. J Clin Endocrinol Metab 2017;102:3172-81.

58. Park S, Church DD, Starck C, Schutzler SE, Azhar G, Kim IY, et al. The impact of Hayward green kiwifruit on dietary protein digestion and protein metabolism. Eur J Nutr 2020 Sep 24 [Epub]. https://doi.org/10.1007/s00394-020-023635.

59. Hellerstein MK. New stable isotope-mass spectrometric techniques for measuring fluxes through intact metabolic pathways in mammalian systems: introduction of moving pictures into functional genomics and biochemical phenotyping. Metab Eng 2004;6:85-100.

60. Martini WZ, Chinkes DL, Wolfe RR. Quantification of DNA synthesis from different pathways in cultured human fibroblasts and myocytes. Metabolism 2004;53:128-33.

61. Brook MS, Wilkinson DJ, Mitchell WK, Lund JL, Phillips BE, Szewczyk NJ, et al. A novel D2O tracer method to quantify RNA turnover as a biomarker of de novo ribosomal biogenesis, in vitro, in animal models, and in human skeletal muscle. Am J Physiol Endocrinol Metab 2017;313:E681-9.

62. Zhang XJ, Rodriguez NA, Wang L, Tuvdendorj D, Wu Z, Tan A, et al. Measurement of precursor enrichment for calculating intramuscular triglyceride fractional synthetic rate. J Lipid Res 2012;53:119-25.

63. Asghar R, Chondronikola M, Dillon EL, Durham WJ, Por- 
ter $\mathrm{C}, \mathrm{Wu} \mathrm{Z}$, et al. Quantification of muscle triglyceride synthesis rate requires an adjustment for total triglyceride content. J Lipid Res 2018;59:2018-24.

64. Katanik J, McCabe BJ, Brunengraber DZ, Chandramouli V, Nishiyama FJ, Anderson VE, et al. Measuring gluconeogenesis using a low dose of $2 \mathrm{H} 2 \mathrm{O}$ : advantage of isotope fractionation during gas chromatography. Am J Physiol Endocrinol Metab 2003;284:E1043-8.

65. Wang Y, Kwon H, Su X, Wondisford FE. Glycerol not lactate is the major net carbon source for gluconeogenesis in mice during both short and prolonged fasting. Mol Metab 2020;31:36-44.

66. Sunny NE, Parks EJ, Browning JD, Burgess SC. Excessive hepatic mitochondrial TCA cycle and gluconeogenesis in humans with nonalcoholic fatty liver disease. Cell Metab 2011;14:804-10.

67. Vatner DF, Majumdar SK, Kumashiro N, Petersen MC, Rahimi Y, Gattu AK, et al. Insulin-independent regulation of hepatic triglyceride synthesis by fatty acids. Proc Natl Acad Sci U S A 2015;112:1143-8.

68. Gasier HG, Riechman SE, Wiggs MP, Previs SF, Fluckey JD. A comparison of $2 \mathrm{H} 2 \mathrm{O}$ and phenylalanine flooding dose to investigate muscle protein synthesis with acute exercise in rats. Am J Physiol Endocrinol Metab 2009;297: E252-9.

69. Wang SP, Zhou D, Yao Z, Satapati S, Chen Y, Daurio NA, et al. Quantifying rates of glucose production in vivo following an intraperitoneal tracer bolus. Am J Physiol Endocrinol Metab 2016;311:E911-21.

70. Wojtaszewski JF, Nielsen JN, Richter EA. Invited review: effect of acute exercise on insulin signaling and action in humans. J Appl Physiol (1985) 2002;93:384-92.

71. Burd NA, West DW, Rerecich T, Prior T, Baker SK, Phillips SM. Validation of a single biopsy approach and bolus protein feeding to determine myofibrillar protein synthesis in stable isotope tracer studies in humans. Nutr Metab (Lond) 2011;8:15.

72. Jaleel A, Short KR, Asmann YW, Klaus KA, Morse DM, Ford GC, et al. In vivo measurement of synthesis rate of individual skeletal muscle mitochondrial proteins. Am J Physiol Endocrinol Metab 2008;295:E1255-68.

73. Miller BF, Wolff CA, Peelor FF 3rd, Shipman PD, Hamilton KL. Modeling the contribution of individual proteins to mixed skeletal muscle protein synthetic rates over increasing periods of label incorporation. J Appl Physiol (1985) 2015;118:655-61.
74. Kim IY, Schutzler S, Schrader A, Spencer H, Kortebein P, Deutz NE, et al. Quantity of dietary protein intake, but not pattern of intake, affects net protein balance primarily through differences in protein synthesis in older adults. Am J Physiol Endocrinol Metab 2015;308:E21-8.

75. Burd NA, Andrews RJ, West DW, Little JP, Cochran AJ, Hector AJ, et al. Muscle time under tension during resistance exercise stimulates differential muscle protein subfractional synthetic responses in men. J Physiol 2012;590: 351-62.

76. Biolo G, Chinkes D, Zhang XJ, Wolfe RR. Harry M. Vars Research Award. A new model to determine in vivo the relationship between amino acid transmembrane transport and protein kinetics in muscle. JPEN J Parenter Enteral Nutr 1992;16:305-15.

77. Hines KM, Ford GC, Klaus KA, Irving BA, Ford BL, Johnson KL, et al. Application of high-resolution mass spectrometry to measure low abundance isotope enrichment in individual muscle proteins. Anal Bioanal Chem 2015;407:4045-52.

78. Groennebaek T, Jespersen NR, Jakobsgaard JE, Sieljacks P, Wang J, Rindom E, et al. Skeletal muscle mitochondrial protein synthesis and respiration increase with low-load blood flow restricted as well as high-load resistance training. Front Physiol 2018;9:1796.

79. Drake JC, Yan Z. Mitophagy in maintaining skeletal muscle mitochondrial proteostasis and metabolic health with ageing. J Physiol 2017;595:6391-9.

80. Fernandez-Calleja JMS, Bouwman LMS, Swarts HJM, Oosting A, Keijer J, van Schothorst EM. Extended indirect calorimetry with isotopic $\mathrm{CO} 2$ sensors for prolonged and continuous quantification of exogenous vs. total substrate oxidation in mice. Sci Rep 2019;9:11507.

81. Coyle EF, Jeukendrup AE, Oseto MC, Hodgkinson BJ, Zderic TW. Low-fat diet alters intramuscular substrates and reduces lipolysis and fat oxidation during exercise. Am J Physiol Endocrinol Metab 2001;280:E391-8.

82. Romijn JA, Coyle EF, Hibbert J, Wolfe RR. Comparison of indirect calorimetry and a new breath $13 \mathrm{C} / 12 \mathrm{C}$ ratio method during strenuous exercise. Am J Physiol 1992;263(1 Pt 1):E64-71.

83. Luiking YC, Poeze M, Deutz NE. Arginine infusion in patients with septic shock increases nitric oxide production without haemodynamic instability. Clin Sci (Lond) 2015; 128:57-67.

84. Castillo L, Beaumier L, Ajami AM, Young VR. Whole 
body nitric oxide synthesis in healthy men determined from $[15 \mathrm{~N}]$ arginine-to-[15N]citrulline labeling. Proc Natl Acad Sci U S A 1996;93:11460-5.

85. Lau T, Owen W, Yu YM, Noviski N, Lyons J, Zurakowski $\mathrm{D}$, et al. Arginine, citrulline, and nitric oxide metabolism in end-stage renal disease patients. J Clin Invest 2000;105: 1217-25.

86. Marini JC. Arginine and ornithine are the main precursors for citrulline synthesis in mice. J Nutr 2012;142:572-80.

87. Chung ST, Chacko SK, Sunehag AL, Haymond MW. Measurements of gluconeogenesis and glycogenolysis: a methodological review. Diabetes 2015;64:3996-4010.

88. Ekberg K, Landau BR, Wajngot A, Chandramouli V, Efendic $\mathrm{S}$, Brunengraber $\mathrm{H}$, et al. Contributions by kidney and liver to glucose production in the postabsorptive state and after $60 \mathrm{~h}$ of fasting. Diabetes 1999;48:292-8.

89. Tigas S, Sunehag A, Haymond MW. Metabolic adaptation to feeding and fasting during lactation in humans. J Clin Endocrinol Metab 2002;87:302-7.

90. Kaplan W, Sunehag AL, Dao H, Haymond MW. Short-term effects of recombinant human growth hormone and feeding on gluconeogenesis in humans. Metabolism 2008;57:72532.

91. Sun RC, Fan TW, Deng P, Higashi RM, Lane AN, Le AT, et al. Noninvasive liquid diet delivery of stable isotopes into mouse models for deep metabolic network tracing. Nat Commun 2017;8:1646.

92. Lee WN, Boros LG, Puigjaner J, Bassilian S, Lim S, Cascante M. Mass isotopomer study of the nonoxidative pathways of the pentose cycle with [1,2-13C2]glucose. Am J Physiol 1998;274:E843-51.

93. Brooks GA, Wolfel EE, Groves BM, Bender PR, Butterfield GE, Cymerman A, et al. Muscle accounts for glucose disposal but not blood lactate appearance during exercise after acclimatization to 4,300m. J Appl Physiol (1985) 1992;72:2435-45.

94. Song JD, Alves TC, Befroy DE, Perry RJ, Mason GF, Zhang XM, et al. Dissociation of muscle insulin resistance from alterations in mitochondrial substrate preference. Cell Metab 2020;32:726-35.

95. Wolfe RR. The underappreciated role of muscle in health and disease. Am J Clin Nutr 2006;84:475-82.

96. Hellerstein MK, Neese RA. Mass isotopomer distribution analysis: a technique for measuring biosynthesis and turnover of polymers. Am J Physiol 1992;263(5 Pt 1):E9881001.
97. Waterlow JC, Garlick PJ, Millward DJ. Protein turnover in mammalian tissues and in the whole body. Amsterdam: North-Holland Pub. Co.; 1978.

98. Ackermans MT, Pereira Arias AM, Bisschop PH, Endert E, Sauerwein HP, Romijn JA. The quantification of gluconeogenesis in healthy men by (2)H2O and [2-(13)C]glycerol yields different results: rates of gluconeogenesis in healthy men measured with (2)H2O are higher than those measured with [2-(13)C]glycerol. J Clin Endocrinol Metab 2001;86: 2220-6.

99. Mazzeo RS, Brooks GA, Schoeller DA, Budinger TF. Disposal of blood [1-13C]lactate in humans during rest and exercise. J Appl Physiol (1985) 1986;60:232-41.

100. Hasenour CM, Rahim M, Young JD. In vivo estimates of liver metabolic flux assessed by 13c-propionate and 13clactate are impacted by tracer recycling and equilibrium assumptions. Cell Rep 2020;32:107986.

101. Perry RJ, Peng L, Cline GW, Butrico GM, Wang Y, Zhang $\mathrm{XM}$, et al. Non-invasive assessment of hepatic mitochondrial metabolism by positional isotopomer NMR tracer analysis (PINTA). Nat Commun 2017;8:798.

102. Previs SF, Brunengraber $\mathrm{H}$. Methods for measuring gluconeogenesis in vivo. Curr Opin Clin Nutr Metab Care 1998; 1:461-5.

103. Hellerstein MK, Neese RA. Mass isotopomer distribution analysis at eight years: theoretical, analytic, and experimental considerations. Am J Physiol 1999;276:E1146-70.

104. Lee WN, Bassilian S, Ajie HO, Schoeller DA, Edmond J, Bergner EA, et al. In vivo measurement of fatty acids and cholesterol synthesis using D2O and mass isotopomer analysis. Am J Physiol 1994;266(5 Pt 1):E699-708.

105. Shankaran M, King CL, Angel TE, Holmes WE, Li KW, Colangelo M, et al. Circulating protein synthesis rates reveal skeletal muscle proteome dynamics. J Clin Invest 2016; 126:288-302.

106. Toffolo G, Basu R, Dalla Man C, Rizza R, Cobelli C. Assessment of postprandial glucose metabolism: conventional dual- vs. triple-tracer method. Am J Physiol Endocrinol Metab 2006;291:E800-6.

107. Steele R. Influences of glucose loading and of injected insulin on hepatic glucose output. Ann N Y Acad Sci 1959; 82:420-30.

108. Jeukendrup AE, Raben A, Gijsen A, Stegen JH, Brouns F, Saris WH, et al. Glucose kinetics during prolonged exercise in highly trained human subjects: effect of glucose ingestion. J Physiol 1999;515(Pt 2):579-89. 
109. Coggan AR, Kohrt WM, Spina RJ, Bier DM, Holloszy JO. Endurance training decreases plasma glucose turnover and oxidation during moderate-intensity exercise in men. J Appl Physiol (1985) 1990;68:990-6.

110. Romijn JA, Klein S, Coyle EF, Sidossis LS, Wolfe RR. Strenuous endurance training increases lipolysis and triglyceride-fatty acid cycling at rest. J Appl Physiol (1985) 1993;75:108-13.

111. Klein S, Weber JM, Coyle EF, Wolfe RR. Effect of endurance training on glycerol kinetics during strenuous exercise in humans. Metabolism 1996;45:357-61.

112. Messonnier LA, Emhoff CA, Fattor JA, Horning MA, Carlson TJ, Brooks GA. Lactate kinetics at the lactate threshold in trained and untrained men. J Appl Physiol (1985) 2013; 114:1593-602.

113. Kouw IW, Cermak NM, Burd NA, Churchward-Venne TA, Senden JM, Gijsen AP, et al. Sodium nitrate co-ingestion with protein does not augment postprandial muscle protein synthesis rates in older, type 2 diabetes patients. Am J Physiol Endocrinol Metab 2016;311:E325-34.

114. MacDonald AJ, Johns N, Stephens N, Greig C, Ross JA, Small AC, et al. Habitual myofibrillar protein synthesis is normal in patients with upper GI cancer cachexia. Clin Cancer Res 2015;21:1734-40.

115. Fabbrini E, Magkos F, Conte C, Mittendorfer B, Patterson BW, Okunade AL, et al. Validation of a novel index to assess insulin resistance of adipose tissue lipolytic activity in obese subjects. J Lipid Res 2012;53:321-4.

116. Schricker T, Lattermann R, Fiset P, Wykes L, Carli F. Inte- grated analysis of protein and glucose metabolism during surgery: effects of anesthesia. J Appl Physiol (1985) 2001; 91:2523-30.

117. Kowalski GM, De Souza DP, Burch ML, Hamley S, Kloehn J, Selathurai A, et al. Application of dynamic metabolomics to examine in vivo skeletal muscle glucose metabolism in the chronically high-fat fed mouse. Biochem Biophys Res Commun 2015;462:27-32.

118. Hui S, Ghergurovich JM, Morscher RJ, Jang C, Teng X, Lu $\mathrm{W}$, et al. Glucose feeds the TCA cycle via circulating lactate. Nature 2017;551:115-8.

119. Bowe JE, Franklin ZJ, Hauge-Evans AC, King AJ, Persaud SJ, Jones PM. Metabolic phenotyping guidelines: assessing glucose homeostasis in rodent models. J Endocrinol 2014; 222:G13-25.

120. Young JD. (13)C metabolic flux analysis of recombinant expression hosts. Curr Opin Biotechnol 2014;30:238-45.

121. Buescher JM, Antoniewicz MR, Boros LG, Burgess SC, Brunengraber $\mathrm{H}$, Clish $\mathrm{CB}$, et al. A roadmap for interpreting (13)C metabolite labeling patterns from cells. Curr Opin Biotechnol 2015;34:189-201.

122. Antoniewicz MR. 13C metabolic flux analysis: optimal design of isotopic labeling experiments. Curr Opin Biotechnol 2013;24:1116-21.

123. Antoniewicz MR, Kelleher JK, Stephanopoulos G. Determination of confidence intervals of metabolic fluxes estimated from stable isotope measurements. Metab Eng 2006; 8:324-37. 